\title{
Analisis Lingkungan Kerja dan Pengawasan Terhadap Kepuasan Kerja Karyawan PT. Pos Indonesia (Persero) Palembang
}

\author{
Muhammad Kurniawan ${ }^{1}$, Joni Iswan ${ }^{2}$, Vicky Saherty Yahya ${ }^{3}$ \\ ${ }^{1}$ Fakultas Ekonomi dan Bisnis Universitas PGRI Palembang, iwanusman220516@gmail.com \\ ${ }^{2}$ Fakultas Saint dan Teknologi Universitas PGRI Palembang, joni.iswan@gmail.com \\ ${ }^{3}$ Fakultas Ekonomi dan Bisnis Universitas PGRI Palembang, vickysaherty@gmail.com
}

\begin{abstract}
ABSTRAK
Tujuan dari penelitian ini adalah untuk mengetahui pengaruh Lingkungan Kerja dan Pengawasan terhadap Kepuasan Kerja Karyawan PT. Pos Indonesia (Persero) Palembang. Sampel dalam penelitian ini adalah karyawan PT. Pos Indonesia (Persero) Palembang dengan penyebaran kuisioner untuk 48 orang karyawan. Teknik dalam penelitian ini menggunakan metode kuantitatif yaitu metode dalam bentuk data dan angka dengan pendekatan deskriptif yaitu merumuskan dan menafsirkan data dan angka. Adapun variabel yang diteliti kepuasan kerja sebagai variabel terikat, lingkungan kerja dan pengawasan sebagai variabel bebas. Dari hasil pengujian uji $\mathrm{t}$ diperoleh nilai signifikan lingkungan kerja $\left(X_{1}\right)$ sebesar $0,000<0,05$. Hal ini berarti $\mathrm{H}_{0}$ ditolakHa diterima yang artinya variabel lingkungan kerja berpengaruh signifikan terhadap kepuasan kerja. Sedangkan nilai signifikan pengawasan $\left(\mathrm{X}_{2}\right)$ terhadap kepuasan kerja sebesar $0,198<0,05$. Hal ini berarti $\mathrm{H}_{a}$ ditolak dan $\mathrm{H}_{0}$ diterima yang artinya variabel pengawasan tidak berpengaruhsignifikan terhadap kepuasan kerja. Dan hasil uji f diperoleh nilai signifikan sebesar $0,000<0,05 \mathrm{H}_{0}$ ditolak dan $\mathrm{H}_{\mathrm{a}}$ diterima sehingga dapat disimpulkan bahwa secara simultan lingkungan kerja $\left(X_{1}\right)$ dan pengawasan $\left(X_{2}\right)$ berpengaruh signifikan terhadap kepuasan kerja karyawan PT. Pos Indonesia (Persero) Palembang.
\end{abstract}

Kata Kunci: Lingkungan Kerja, Pengawasan dan Kepuasan Kerja.

\begin{abstract}
The purpose of this study was to determine the effect of the Work Environment and Supervision on Job Satisfaction of PT. Pos Indonesia (Persero) Palembang. The sample in this study were employees of PT. Pos Indonesia (Persero) Palembang by distributing questionnaires to 48 employees. The technique in this research uses quantitative methods, namely methods in the form of data and numbers with a descriptive approach, namely formulating and interpreting data and numbers. The variables studied were job satisfaction as the dependent variable, work environment and supervision as independent variables. From the results of the $t$ test, it was found that the significant value of the work environment (X1) was $0.000<0.05$. This means that $\mathrm{HO}$ is rejected, $\mathrm{Ha}$ is accepted, which means that the work environment variable has a significant effect on job satisfaction. Meanwhile, the significant value of supervision (X2) on job satisfaction is $0.198<0.05$. This means that $\mathrm{Ha}$ is rejected and $\mathrm{HO}$ is accepted, which means that the monitoring variable has no significant effect on job satisfaction. And the results of the f test obtained a significant value of $0.000<0.05$. HO is rejected and $\mathrm{Ha}$ is accepted, so it can be concluded that simultaneously the work environment (X1) and supervision (X2) have a significant effect on job satisfaction of employees of PT. Pos Indonesia (Persero) Palembang.
\end{abstract}

Keywords: Work Environment, Supervision and Job Satisfaction.

\section{A. PENDAHULUAN}

Menurut Soedarso (2015:95), lingkungan kerja merupakan lingkungan dimana para karyawan dapat melaksanakan tugasnya sehari-hari dengan keseluruhan sarana dan prasarana kerja yang diperlukan untuk melaksanakan tugas-tugas tersebut. Lingkungan kerja merupakan salah satu faktor penting dalam menciptakan kepuasan karyawan. Karena lingkungan kerja mempunyai pengaruh langsung 
terhadap karyawan didalam menyelesaikan pekerjaan yang pada akhirnya akan meningkatkan kinerjaorganisasi dan kepuasan karyawan.

Menurut Sutrisno (2015:73), kepuasan kerja merupakan suatu kondisi psikologis yang menyenangkan atau perasaan karyawan yang sangat subjektif dan sangat tergantung pada individu yang bersangkutan dan lingkungan kerjanya.

Menurut Manullang (2012:174), tujuan utama pengawasan ialah mengusahakan agar apa yang direncanakan menjadi kenyataan. Oleh karena itu, agar sistem pengawasan benar-benar efektif artinya dapat merealisasi tujuannya, maka suatu sistem pengawasan setidak-tidaknya harus dapat dengan segera melaporkan adanya penyimpangan-penyimpangan dari rencana. Dengan melakukan pengawasan yang baik, maka diharapkan para karyawan akan menghasilkan suatu kerja yang optimal. Semakin lancar kerja dan disertai pengawasan yang baik maka pekerjaan itu akan berhasil dengan baik dan mendorong karyawan lebih giat dalam bekerja dan menghasilkan pekerjaan dengan semangat yang baik.Jika pengawasan nya berjalan dengan tidak optimal maka karyawan akan sering menunda-nunda pekerjaan, dan penyelesaian tugas karyawan tidak sesuai standar dan tidak adanya prosedur yang jelas dalam pengawasan.

Hasil penelitian Kurniawan, Hendri tahun (2017) hasil penelitian menunjukkan bahwa secara parsial dan simultan terdapat pengaruh positif dan signifikan antara variabel lingkungan kerja dan pengawasan terhadap kepuasan kerja.

Hasil penelitian Oktariansyah (2012) terdapat pengaruh yang signifikan antara lingkungan kerja fisik dengan motivasi kerja karyawan CV. Sedulur Palembang.

Hasil penelitian Adriansyah (2019) dimana hasil penelitiannya terdapat pengaruh pengawasan yang dominan atau lebih besar terhadap kepuasan kerja dibandingkan dengan lingkungan kerja terhadap kepuasan kerja karyawan PT. Virajaya Riauputra Kampar.

Dari hasil penelitian terdahulu dapat simpulkan bahwa lingkungan kerja dan pengawasan berpengaruh positif dan signifikan terhadap kepuasan kerja.Perbedaan penelitian ini dengan penelitian sebelumnya antara lain objek dan tahun data penelitian.

\section{B. KAJIAN TEORI}

\section{LINGKUNGAN KERJA}

Menurut Soedarso (2015:95), lingkungan kerja merupakan lingkungan dimana para karyawan dapat melaksanakan tugasnya sehari-hari dengan keseluruhan sarana dan prasarana kerja yang diperlukan untuk melaksanakan tugas-tugas tersebut.

Menurut Sedarmayanti (2011:21), lingkungan kerja merupakan keseluruhan alat perkakas dan bahan yang dihadapi, lingkungan sekitarnya dimana seseorang bekerja, metode kerjanya, serta pengaturan kerjanya baik sebagai perseorangan maupun kelompok.

Menurut Sedarmayanti (2011:21) indikator yang mempengaruhi lingkungan kerja adalah:
a. Penerangan atau cahaya
b. Sirkulasi Udara
c. Kebisingan ditempat kerja
d. Bau tidak sedap
e. Keamanan di tempat kerja 
Menurut Sedarmayanti (2011:21) secara garis besar jenis lingkungan kerja terbagi menjadi 2 yaitu:

a. lingkungan kerja fisik

b. lingkungan kerja non fisik.

\section{PENGAWASAN}

Menurut Saefullah (2012:317), pengawasan sebagai proses dalam menetapkan ukuran kinerja dan pengambilan tindakan yang dapat mendukung pencapaian hasil yang diharapkan sesuai dengan kinerja yang telah ditetapkan tersebut (Controlling is the process of measuring performance and taking

kenyataan. Oleh karena itu, agar sistem pengawasan benar-benar efektif artinya dapat merealisasi tujuannya, maka suatu sistem pengawasan setidaktidaknya action to ensure desired results).

Menurut Manullang (2012:174), tujuan utama pengawasan ialah mengusahakan agar apa yang direncanakan menjadi harus dapat dengan segera melaporkan adanya penyimpangan-penyimpangan dari rencana.

Menurut Saefullah (2012:317), menyebutkan beberapa faktor yang mempengaruhi pengawasan kerja adalah:

a. Perubahan yang selalu terjadi dari luar maupun dari dalam organisasi.

b. Kompleksitas organisasi memerlukan pengawasan formal karena adanya desentralisasi kekuasaan.

c. Kesalahan penyimpangan yang dilakukan oleh anggota organiasi memerlukan pengawasan.

Indikator pengawasan menurut Jufrizen (2016:20-21) adalah:

a. Menentukan ukuran pelaksanaan

b. Memberikan penilaian

c. Mengadakan korektif

\section{KEPUASAN KERJA}

Menurut Sutrisno (2015:73), kepuasan kerja merupakan suatu kondisi psikologis yang menyenangkan atau perasaan karyawan yang sangat subjektif dan sangat tergantung pada individu yang bersangkutan dan lingkungan kerjanya.

Menurut Sinambela (2016:308) faktor-faktor yang mempengaruhi kepuasan kerja adalah:
a. Kesempatan untuk maju
b. Keamanan kerja
c. Gaji
d. Perusahaan dan manajemen
e. Pengawasan
f. Faktor interistik dari pekerjaan
g. Kondisi kerja
h. Aspek sosial
i. Komunikasi
j. Fasilitas

Menurut Sutrisno (2015:80) indikator kepuasan kerja adalah:

a. Faktor psikologis

b. Faktor sosial 


\section{c. Faktor fisik \\ d. Faktor finansial}

\section{METODE PENELITIAN}

Berdasarkan jenis dan pendekatan penelitian, maka penelitian ini termasuk dalam kategori penelitian kuantitatif, yaitu penelitian yang bertujuan untuk mengukur data dan menerapkan beberapa bentuk analisis statistik. Penelitian ini menguji pengaruh variabel bebas terhadap variabel terikat.

Menurut Sugiono (2017:35), metode kuantitatif dapat diartikan sebagai metode penelitian yang berlandaskan pada filsafat positivisme, digunakan untuk meneliti pada populasi atau sampel tertentu, pengumpulan data menggunakan instrumen penelitian, analisis data bersifat kuantitatif/statistik, dengan tujuan untuk menguji hipotesis yang telah ditetapkan. Penelitian ini dimaksudkan untuk menggali fakta tentang kepuasan kerja karyawan PT. Pos Indonesia (Persero) Palembang.

\section{Variabel Penelitian `}

Menurut Sugiyono (2017:95), menyatakan bahwa variabel penelitian pada dasarnya adalah segala sesuatu yang berbentuk apa saja yang ditetapkan oleh peneliti untuk di pelajari sehingga diperoleh informasi tentang hal tersebut kemudian ditarik kesimpulannya.

Menurut Sugiyono (2017:96), macam-macam variabel dalam penelitian dapat dibedakan menjadi:

a. Variabel bebas (Independen) variabel yang mempengaruhi atau yang menjadi sebab perubahannya atau timbulnya variabel dependen. Variabel bebas Lingkungan kerja $\left(\mathrm{X}_{1}\right)$ dan Pengawasan $\left(\mathrm{X}_{2}\right)$.

b. Variabel terikat (Dependen) variabel yang dipengaruhi atau yang menjadi akibat, karena adanya variabel bebas. Variabel bebas Kepuasan Kerja (Y).

\section{Definisi Operasional Istilah/ Variabel}

Menurut Sugiyono (2017:95), Variabel penelitian segala sesuatu yang berbentuk apa saja yang ditetapkan oleh penelitian untuk dipelajari sehingga diperoleh informasi tentang hal tersebut, kemudian ditarik kesimpulannya.

Dalam penelitian ini yang menjadi variabel bebas (Independen) adalah lingkungan kerja $\left(X_{1}\right)$ dan pengawasan $\left(X_{2}\right)$ dan sedangkan variabel terikat (Dependen) adalah kepuasan (Y). 
Tabel Devinisi Operasional Variabel

\begin{tabular}{|c|c|c|c|c|}
\hline No & Variabel & Definisi & Indikator & Skala \\
\hline 1. & $\begin{array}{l}\text { Lingkungan } \\
\text { Kerja }\left(X_{1}\right)\end{array}$ & $\begin{array}{l}\text { Lingkungan kerja } \\
\text { merupakan } \\
\text { keseluruhan alat } \\
\text { perkakas dan bahan } \\
\text { yang dihadapi, } \\
\text { lingkungan sekitarnya } \\
\text { dimana seseorang } \\
\text { bekerja, metode } \\
\text { kerjanya, serta } \\
\text { pengaturan kerjanya } \\
\text { baik sebagai } \\
\text { perseorangan } \\
\text { maupun kelompok. } \\
\text { Sedarmayanti } \\
\text { (2011:21) }\end{array}$ & $\begin{array}{l}\text { 1. Penerangan } \\
\text { /cahaya } \\
\text { 2. Sirkulasi udara } \\
\text { ditempat kerja } \\
\text { 3. Kebisingan } \\
\text { ditempat kerja } \\
\text { 4. Bau tidak sedap } \\
\text { 5. Keamanan } \\
\text { Sedarmayanti (2011:21) }\end{array}$ & Ordinal \\
\hline 2. & $\begin{array}{l}\text { Pengawasan } \\
\left(\mathrm{X}_{2}\right)\end{array}$ & $\begin{array}{l}\text { pengawasan adalah } \\
\text { kegiatan yang } \\
\text { membandingkan atau } \\
\text { mengukur apa yang } \\
\text { sedang atau sudah } \\
\text { dilaksanakan dengan } \\
\text { kriteria norma } \\
\text { standar atau } \\
\text { rencana-rencana } \\
\text { yang telah } \\
\text { ditetapkan. } \\
\text { Jufrizen }(2016: 20)\end{array}$ & $\begin{array}{ll}\text { 1. } & \text { Menentukan } \\
\text { ukuran } \\
\text { pelaksanaan } \\
\text { 2. Memberikan } \\
\text { penilaian } \\
\text { 3. Mengadakan } \\
\text { korektif } \\
\text { Jufrizen (2016:20-21) }\end{array}$ & Ordinal \\
\hline 3. & $\begin{array}{l}\text { Kepuasan } \\
\text { Kerja }(Y)\end{array}$ & $\begin{array}{l}\text { kepuasan kerja } \\
\text { merupakan suatu } \\
\text { kondisi psikologis } \\
\text { yang menyenangkan } \\
\text { atau perasaan } \\
\text { karyawan yang } \\
\text { sangat subjektif dan } \\
\text { sangat tergantung } \\
\text { pada individu yang } \\
\text { bersangkutan dan } \\
\text { lingkungan kerjanya. } \\
\text { Sutrisno (2015:73) }\end{array}$ & $\begin{array}{l}\text { 1. Faktor psikologis } \\
\text { 2. Faktor sosial } \\
\text { 3. Faktor fisik } \\
\text { 4. Faktor finansial } \\
\text { Sutrisno }(2015: 80)\end{array}$ & Ordinal \\
\hline
\end{tabular}

\section{Populasi dan Sampel}

1) Populasi

Menurut Sugiyono (2017:148), Populasi adalah wilayah generalisasi yang terdiri atas obyek/subyek yang mempunyai kualitas dan karakteristik tertentu yang diterapkan oleh peneliti untuk dipelajari dan kemudian ditarik kesimpulannya. Jadi populasi dalam penelitian ini adalah karyawan PT. Pos Indonesia (Persero) Palembang.

2) Sampel

Menurut Sugiyono (2017:149), Sampel adalah bagian dari jumlah dan karakteristik yang dimiliki oleh populasi tersebut. Jumlah sampel dalam 
penelitian ini adalah seluruh populasi yaitu sebanyak 48 orangdiambil dari bagian unit kerja Sumber Daya Manusia (SDM), Administrasi, Pemasaran, Loket dan Pengiriman Barang/Sarana. Adapun metode penarikan sampelnya adalah teknik sampel jenuh. Sampel jenuh adalah teknik penentuan sampel bila semua anggota populasi digunakan sebagai sampel.

\section{Sumber Data}

Menurut Sugiyono (2017:225), jenis data yang digunakan dalam penelitian ini adalah sebagai berikut:

a. Data Primer

Sumber Data Primer adalah data yang langsung memberikan data kepada pengumpul data. Data yang diperoleh dari responden melalui kuisioner, kelompok fokus, dan panel, atau juga data hasil wawancara peneliti dengan narasumber.

b. Data Sekunder

Sumber Data Sekunder adalah data yang tidak langsung memberikan data kepada pengumpul data, misalnya data yang didapat catatan, buku majalah, artikel buku-buku sebagai teori, dan sabagainya.

Didalam penelitian ini penulis menggunakan sumber data primer dan sekunder.

\section{Teknik Pengumpulan Data}

Menurut Sugiyono (2017:375), teknik pengumpulan data merupakan langkah yang paling utama dalam penelitian, karena tujuan utama dari penelitian adalah mendapatkan data. Macam-macam teknik pengumpulan data yang dapat dilakukan adalah observasi (pengamatan), interview (wawancara), kuisioner (angket), dokumentasi dan gabungan keempatnya.

a. Observasi (Pengamatan)

Observasi merupakan suatu proses biologis dan psikologis. Teknik pengumpulan data dengan observasi digunakan bila penelitian berkenaan dengan perilaku manusia, proses kerja, gejala kerja-gejala alam dan responden yang diamati tidak terlalu besar.

b. Interview (Wawancara)

Wawancara merupakan teknik pengumpulan data dan dimana pewawancara (peneliti atau yang diberi tugas melakukan pengumpulan data) dalam mengumpulkan data mengajukan suatu pertanyaan kepada yang diwawancarai.

c. Kuisoner (Angket)

Kuisioner merupakan teknik pengumpulan data dimana responden mengisi pertanyan atau pernyataan kemudian setelah diisi dengan lengkap mengembalikan kepada peneliti.

d. Dokumentasi

Dokumentasi merupakan catatan peristiwa yang sudah berlalu. Dokumen bisa berbentuk tulisan, gambar, atau karya-karya monumental dari seseorang.

Didalam penelitian ini peneliti hanya menggunakan teknik pengumpulan data kuisioner (angket) dan dokumentasi. 


\section{HASIL PENELITIAN}

\section{Uji Normalitas}

Tabel Hasil Uji Normalitas

\begin{tabular}{|c|c|c|c|c|}
\hline & & $\begin{array}{l}\text { LINGKUNGAN } \\
\text { KERJA X }_{1}\end{array}$ & $\begin{array}{c}\text { PENGAWASAN } \\
X_{2}\end{array}$ & $\begin{array}{c}\text { KEPUASAN } \\
\text { KERJA } \\
\text { Y }\end{array}$ \\
\hline $\bar{N}$ & & 48 & 48 & 48 \\
\hline Normal & Mean & 42.7917 & 40.9792 & 35.4583 \\
\hline Paramenter & Std.Deviation & 5.80886 & 3.65239 & 3.98913 \\
\hline Most & Absolute & 107 & 168 & 164 \\
\hline Extreme & Positive & 107 & 168 & 140 \\
\hline Differences & Negative & -105 & -066 & -164 \\
\hline Test & & 744 & 1.165 & 1.138 \\
\hline Statistik & & & & \\
\hline $\begin{array}{l}\text { Asymp.Sig. } \\
\text { (2-tailed) }\end{array}$ & & 638 & 132 & 150 \\
\hline
\end{tabular}

Sumber : Hasil pengolahan data 2020

Hasil uji normalitas pada tabel di atas dapat diketahui bahwa berdasarkan uji kolmogrov-smirnov,diperoleh hasil output asymp.sig. (2-tailed)Sig >a $(=0,05)$ menunjukkan bahwa data tersebut terdistribusi secara normal.

\section{Uji Multikolinieritas}

\begin{tabular}{ccc}
\multicolumn{3}{c}{ Tabel Hasil Uji Multikolinieritas } \\
\hline Variabel & Tolerance & VIF \\
\hline Kerja Lingkungan & 0,985 & 1.016 \\
Pengawasan & 0,985 & 1.016 \\
\hline Sumber : Hasil pengolahan data 2020
\end{tabular}

Sumber : Hasil pengolahan data 2020

Hasil uji multikolinieritas pada tabel di atas diketahui bahwa nilai tolerance lebih besar dari 0,10 dan nilai variance inflaction factor $(\mathrm{VIF})<0,10$ dari variabel. Pada variabel lingkungan kerja $\left(X_{1}\right)$ dan pengawasan $\left(X_{2}\right)$ nilai tolerance sebesar $0,985>$ 0,10 . Sedangkan, nilai VIF pada variabel lingkungan kerja $\left(X_{1}\right)$ dan pengawasan $\left(X_{2}\right)$ sebesar $1.016<10$. Maka dapat disimpulkan bahwa tidak terjadi multikolinieritas pada penelitian ini.

\section{Uji Heteroskedasitas}

Tabel Hasil Uji Heteroskedasitas

\begin{tabular}{|c|c|c|c|}
\hline Variabel & Signifikan & $\alpha=0,05$ & Keterangan \\
\hline Lingkungan Kerja & $-0,004$ & 0,05 & $\begin{array}{c}\text { Tidak terjadi } \\
\text { heteroskedastisitas }\end{array}$ \\
\hline Pengawasan & $-0,149$ & 0,05 & $\begin{array}{c}\text { Tidak terjadi } \\
\text { heteroskedasstisitas }\end{array}$ \\
\hline
\end{tabular}

Sumber: Hasil pengolahan data 2020

Hasil uji heteroskedasitas pada tabel di atas menunjukan bahwa nilai signifikansi variabel-variabel independen lebih besar dari 005 (sig > 0,05) dengan demikian bahwa model regresi yang dipakai tidak terjadi heteroskedastisitas. 


\section{Analisis Regresi Linier Sederhana}

Tabel Hasil Uji Analisis Regresi Linier Sederhana Lingkungan Kerja
\begin{tabular}{cccccc} 
Variabel & B & std.error & Beta & t & Sig \\
\hline Constant & 18.363 & 3.556 & & 5.164 & 0,000 \\
Lingkungan Kerja & 0,400 & 0,082 & 0,582 & 4.851 & 0,000 \\
\hline
\end{tabular}

Sumber : Hasil pengolahan data 2020

Hasil uji regresi linier sederhana variabel lingkungan kerja dengan nilai $Y=$ $18,363+0,400 x$. Konstanta sebesar 18,363 artinya apabila lingkungan kerja nilainya adalah 0 maka kepuasan kerja sebesar 18,363. Sedangkan koefisien regresi lingkungan kerja mengalami perubahan 1 kepuasan kerja mengalami peningkatan 0,400 . Jadi, jika lingkungan kerja meningkat maka kepuasan kerja juga meningkat.

Tabel Analisis Regresi Linier Sederhana Pengawasan

\begin{tabular}{llllcc}
\hline \multicolumn{1}{c}{ Variabel } & B & std. error & Beta & T & sig \\
\hline Constant & 31.768 & 6.602 & & 4,812 & 0,000 \\
Pengawasan & 0,090 & 0,160 & 0,082 & 0,561 & 0,577 \\
\hline
\end{tabular}

Sumber : Hasil pengolahan data 2020

Hasil uji regresi linier sederhana variabel pengawasan dengan nilai $Y=31,768$ $+0,090 x$. Konstanta sebesar 31,768 artinya apabila pengawasan nilainya adalah 0 maka kepuasan kerja sebesar 31,768 . Sedangkan koefisien regresi pengawasan mengalami perubahan 1 kepuasan kerja mengalami peningkatan 0,090. Jadi, jika pengawasan meningkat maka kepuasan kerja juga meningkat.

\section{Analisis Linier Berganda}

\begin{tabular}{cc} 
Tabel Hasil Uji Analisis Linier Berganda \\
\hline Variabel & Nilai \\
\hline a(konstanta) & 10,779 \\
Lingkungan Kerja & 0,413 \\
Pengawasan & 0,171 \\
Error & 6,792
\end{tabular}

Sumber : Hasil pengolahan data 2020

hasil persamaan regresi sebagai berikut :

$Y=a+b_{1} X_{1}+b_{2} X_{2}+e$

$Y=10,779+0,413 X_{1}+0,171 X_{2}+6,792$

Keterangan :

$\mathrm{Y}=$ Kepuasan Kerja

$a=10,779$

$b_{1}=0,413$

$b_{2}=0,171$ 
$\mathrm{X}_{1}$ = Lingkungan Kerja

$\mathrm{X}_{2}=$ Pengawasan

$e_{=}$standard kesalahan (tingkat error)

Dari hasil pengujian regresi liniear berganda terdapat persamaan yang menunjukkan koefesien regresi dari 2 (dua) variabel bebas $\left(b_{1}\right.$ dan $b_{2}$ ) bertanda positif (+). Bilangan konstanta (a) mempunyai nilai sebesar 10,779 menyatakan bahwa jika mengabaikan lingkungan kerja $\left(X_{1}\right)$ dan pengawasan $\left(X_{2}\right)$ maka nilai kepuasan kerja adalah 10,779. Jadi, tetap ada kepuasan kerja walaupun nilai $X_{1}$ dan $\mathrm{X}_{2}$ bernilai nol (0) terhadap $\mathrm{Y}$.

\section{Analisis Koefisien Korelasi}

Tabel Hasil Uji Analisi Koefisien Kerelasi

\begin{tabular}{cccc}
\hline Variabel & $\begin{array}{c}\text { Person } \\
\text { Correlation }\end{array}$ & $\begin{array}{c}\text { Signifikan } \\
0,05\end{array}$ & $\begin{array}{c}\text { Tingkat } \\
\text { Hubungan }\end{array}$ \\
\hline $\begin{array}{c}\text { Lingkungan } \\
\text { kerja } \\
\text { terhadap } \\
\text { kepuasan } \\
\text { kerja }\end{array}$ & 0,582 & 0,000 & $\begin{array}{c}\text { Sangat } \\
\text { rendah }\end{array}$ \\
$\begin{array}{c}\text { Pengawasan } \\
\text { terhadap } \\
\text { kepuasan } \\
\text { kerja }\end{array}$ & 0,082 & 0,289 & Rendah \\
\hline Sumber: Hasil pengolahan data $\mathbf{2 0 2 0}$ & \\
\end{tabular}

Hasil diatas menunjukkan bahwa lingkungan kerja terhadap kepuasan kerja diperoleh person correlationsebesar 0,582 dengan nilai signifikansi $0,000>0,05$ maka dapat disimpulkan bahwa hubungan antara lingkungan kerja terhadap kepuasan kerja pada tingkat sangat rendah dan tidak terjadi hubungan yang signifikan.Untuk pengawasan terhadap kepuasan kerja diperoleh person correlation sebesar 0,082 dengan nilai signifikansi 0,289>0,05 maka dapat disimpulkan bahwa hubungan pengawasan terhadap kepuasan kerjarendah dan tidak ada hubungan signifikan.

\section{Analisis koefisien Determinasi}

Tabel Hasil Uji Analisis Koefisien Determinasi

\begin{tabular}{llllll}
\hline Variabel & $\mathrm{R}$ & $\begin{array}{l}\mathrm{R} \\
\text { Square }\end{array}$ & $\begin{array}{l}\text { Adjusted } \\
R \text { Square }\end{array}$ & $\begin{array}{l}\text { Std. Error } \\
\text { of the } \\
\text { Estimate }\end{array}$ & $\begin{array}{l}\text { Durbin } \\
\text { Watson }\end{array}$ \\
\hline $\begin{array}{l}\text { lingkungan } \\
\text { kerja } \\
\text { dan }\end{array}$ & 0,602 & 0,363 & 0,334 & 3,25476 & 1,558 \\
pengawasan & & & & & \\
\hline
\end{tabular}

Sumber : Hasil pengolahan data 2020

$R^{2}=\left(r^{2}\right) \times 100 \%$

$=0,363 \times 100 \%=3,63 \%$ 
Hasil diatas menunjukkan nilai koefisien determinasi $\left(R^{2}\right)$ sebesar $3,63 \%$ menunjukkan bahwa pengaruh variabel lingkungan kerja dan pengawasan terhadap kepuasan kerja sebesar 3,63\%. Sedangkan sisanya sebesar 96,37\% dipengaruhi oleh variabel lain atau faktor-faktor yang lain yang tidak termasuk dalam penelitian ini seperti motivasi kerja, disipilin kerja dan budaya kerja.

8. Uji t

Tabel Hasil Uji t

\begin{tabular}{llll}
\hline Variabel & Signifikan & $\alpha=0,05$ & Keterangan \\
\hline $\begin{array}{l}\text { Lingkungan } \\
\text { Kerja }\end{array}$ & 0,000 & 0,05 & Signifikan \\
Pengawasan & 0,198 & 0,05 & $\begin{array}{l}\text { Tidak } \\
\text { signifikan }\end{array}$
\end{tabular}

Sumber : Hasil pengolahan data 2020

Hasil uji t pada tabel di atas untuk menguji pengaruh tiap variabel independen terhadap variabel dependen dengan membandingkan nilai signifikan 0,05, jika signifikan < 0,05 maka variabel tersebut berpengaruh secara signifikan. Sehingga uji t sesuai tabel di atas adalah sebagai berikut :

Menguji pengaruh variabel lingkungan kerja $\left(X_{1}\right)$

Hipotesis 1 : Pengaruh Lingkungan Kerja Terhadap Kepuasan Kerja

Berdasarkan tabel diatas diperoleh nilai signifikan antara lingkungan kerja terhadap kepuasan kerja sebesar $0,000>0,05$, artinya $\mathrm{H}_{0}$ ditolak $\mathrm{H}_{\mathrm{a}}$ diterima, maka dapat disimpulkan bahwa terdapat pengaruh signifikan antara variabel lingkungan kerja terhadap kepuasan kerja.

Menguji pengaruh pengawasan terhadap kepuasan kerja

Hipotesis 2 : Pengaruh Pengawasan Terhadap Kepuasan Kerja

Berdasarkan tabel diatas diperoleh nilai signifikan antara pengawasan terhadap kepuasan kerja sebesar $0,198>0,05$, artinya $\mathrm{H}_{0}$ diterima $\mathrm{H}_{a}$ ditolak, maka dapat disimpulkan bahwa tidak terdapat pengaruh signifikan antara variabel pengawasan terhadap kepuasan kerja.

\section{Uji F}

Tabel Hasil Uji F

\begin{tabular}{llll}
\hline Variabel & Signifikan & $\alpha=0,05$ & Keterangan \\
\hline Lingkungan & 0,000 & 0,05 & Signifikan \\
kerja dan & & \\
pengawasan & & \\
\multicolumn{2}{l}{ Sumber : Hasil pengolahan data 2020 }
\end{tabular}

Dari hasil uji $\mathrm{F}$ diatas diperoleh hasil variabel lingkungan kerja dan pengawasan mempunyai tingkat signifikan lebih kecil $0,05(0,000<0,05)$ berarti $\mathrm{H}_{0}$ ditolak $\mathrm{H}_{\mathrm{a}}$ diterima, sehingga dapat disimpulkan bahwa ada hubungan yang signifikan antara variabel lingkungan kerja dan pengawasan secara simultan atau bersama-sama terhadap kepuasan kerja PT. Pos Indonesia (persero) Palembang.

E. PEMBAHASAN 


\section{Pengaruh Lingkungan Kerja Terhadap Kepuasan Kerja}

Berdasarkan hasil uji t di atas, variabel lingkungan kerja mempunyai nilai sig. $0,000<0,05$. Hal ini berarti $\mathrm{H}_{0}$ ditolak $\mathrm{H}_{a}$ diterima yang artinya variabel lingkungan kerja berpengaruh terhadap kepuasan kerja. Lingkungan kerja merupakan salah satu faktor penting dalam menciptakan kepuasan kerja karyawan. Karena lingkungan kerja mempunyai pengaruh langsung terhadap karyawan didalam menyelesaikan pekerjaan yang pada akhirnya akan meningkatkan kinerja organisasi dan kepuasan karyawan. Suatu kondisi lingkungan kerja dikatakan baik apabila karyawan dapat melaksanakan kegiatan secara optimal, sehat, aman, dan nyaman.

Oleh karena itu penentuan dan penciptaan lingkungan kerja yang baik akan sangat menentukan keberhasilan pencapaian tujuan organisasi. Menurut Soedarso (2015:95), lingkungan kerja merupakan lingkungan dimana para karyawan dapat melaksanakan tugasnya sehari-hari dengan keseluruhan sarana dan prasarana kerja yang diperlukan untuk melaksanakan tugas-tugas tersebut.

Berdasarkan hasil diatas bahwa nilai $b_{1}$ sebesar 0,413 artinya semakin besar lingkungan kerja yang diberikan maka nilai kepuasan kerja karyawan akan semakin meningkat. Hasil penelitian ini mendukung hasil penelitian dari Akila (2017) dimana variabel lingkungan kerja memiliki pengaruh yang signifikan terhadap kepuasan kerja karyawan CV. Timmi Bersaudara Palembang.

\section{Pengaruh Pengawasan Terhadap Kepuasan Kerja}

Berdasarkan hasil uji $\mathrm{t}$ di atas, variabel pengawasan mempunyai nilai sig. $0,198<0,05$. Hal ini bearti $\mathrm{H}_{0}$ diterima $\mathrm{H}_{\mathrm{a}}$ ditolak yang artinya variabel pengawasan tidak berpengaruh positif dan tidak signifikan terhadap kepuasan kerja.

Hasil penelitian ini tidak sejalan dengan hasil dari penelitian Adriansyah (2019) dimana hasil penelitiannya terdapat pengaruh pengawasanyang dominan atau lebih besar terhadap kepuasan kerja dibandingkan dengan lingkungan kerja terhadap kepuasan kerja karyawan PT. Virajaya Riauputra Kampar.

Dan berdasarkan hasil diatas bahwa nilai $b_{2}$ sebesar 0,171 artinya pengawasantidak memiliki pengaruh terhadap kepuasan kerja.

\section{Pengaruh Lingkungan Kerja Dan PengawasanTerhadap Kepuasan Kerja.}

Hasil pengujian Uji $f$ menunjukkan hasilvariabel lingkungan kerja dan pengawasan mempunyai tingkat signifikan lebih kecil 0,05 $(0,000<0,05)$ berarti $\mathrm{H}_{0}$ ditolak $\mathrm{H}_{\mathrm{a}}$ diterima, sehingga dapat disimpulkan bahwa ada hubungan yang signifikan antara variabel lingkungan kerja dan pengawasan secara simultan atau bersama-sama terhadap kepuasan kerja PT. Pos Indonesia (persero) Palembang. Hal ini menunjukkan bahwa untuk meningkatkan kepuasan kerja karyawan harus dilakukan secara bersama-sama agar kepuasan kerja karyawan PT. Pos Indonesia (persero) Palembang tercapai.

Hasil penelitian ini mendukung hasil penelitian dari Kurniawan dan Hendri (2017) dimana variabel lingkungan kerja dan pengawasan memiliki pengaruh yang signifikan terhadap kepuasan kerja diperoleh nilai beta $(\beta)$ sebesar $0,482 t_{\text {hitung }}>t_{\text {tabel }}$ $(4,362>1,997)$ dan signifikasi $0,000<0,05$ berarti ada pengaruh signifikan lingkungan kerja dan pengawasan terhadap kepuasan kerja karyawan. 


\section{E. KESIMPULAN DAN SARAN}

1) Kesimpulan

Penelitian ini bertujuan untuk mengetahui pengaruh dari lingkungan kerja dan pengawasan terhadap kepuasan kerja pada PT. Pos Indonesia (Persero) Palembang. Berdasarkan dari hasil analisis dan pembahasan yang dilakukan dengan menggunakan regresi linier berganda dapat dilihat dari kesimpulan berikut ini:

a. Lingkungan kerja memiliki nilai sig. 0,000<0,05 dan berpengaruh positif dan signifikan terhadap kepuasan kerja karyawan PT. Pos Indonesia (Persero) Palembang.

b. Pengawasan memiliki nilai sig. 0,198< 0,05 dan tidak berpengaruh positif dan signifikan terhadap kepuasan karyawan PT. Pos Indonesia (Persero) Palembang.

c. Lingkungan Kerja dan Pengawasan memiliki pengaruh yang positif dan signifikan secara bersama-sama terhadap kepuasan kerja karyawan PT. Pos Indonesia (Persero) Palembang.

2) Saran

Berdasarkan kesimpulan yang diperoleh di atas, saran yang dapat diberikan adalah sebagai berikut :

a. Dalam rangka peningkatan kepuasan kerja pimpinan hendaknya selalu mempertimbangkan kebijakan yang dibuat, dengan memperhatikan aspekaspek yang memunculkan kepuasan kerja karyawan.

b. Melalui pengawasan dan lingkungan kerja yang sudah tercipta dengan baik, maka hal ini harus tetap dipertahankan dan dijaga, agar kepuasan kerja karyawan terus meningkat.

c. Penelitian mendatang hendaknya mengarahkan peneliti pada objek penelitian yang lebih luas dengan mengambil sektor lain, sehingga dapat diketahui lebih dalam kepuasan kerja secara keseluruhan.

\section{DAFTAR PUSTAKA}

Ardiansyah, Zikri. 2019. Pengaruh pengawasan dan lingkungan kerja terhadap kepuasan kerja karyawan PT. Virajaya Riauputra Kampar. Skripsi Universitas Islam Negeri Sultan Syarif Kasim Riau Pekanbaru 2019.

Jufrizen, 2016. Pengaruh pengawasan terhadap kinerja karyawan melalui disiplin kerja pada PT. Socfin Indonesia. Medan. Jurnal ilmiah manajemen dan bisnis. Vol. 17, No. 02. Oktober 2016.

Kurniawan,.M, Hendri, E. 2017. Faktor-faktor yang menentukan kepuasan kerja pegawai. Jurnal Ekonomi Modernisasi Vol. 13 No. 3.

Manullang, M. 2012. Dasar-dasar Manajemen. Diterbitkan dan dicetak oleh: Gadjah Mada University Press. P.O Box 14, Bulaksumur, Yogyakarta 55281.

Oktariansyah, 2012. Pengaruh Kepemimpinan Dan Lingkungan Kerja Fisik Terhadap Motivasi Kerja Karyawan CV. Sedulur Palembang. Jurnal Media Wahana Ekonomika Vol. 9, No.2, Juli 2012 : 80 - 93 
Saefullah, Kurniawan. 2012. Pengantar Manajemen. Jakarta. Kencana Prenada Media Group.

Sedarmayanti. 2011. Manajemen sumber daya manusia, reformasi birokrasi dan manajemen pegawai negeri sipil (cetakan kelima). Bandung: PT. Refika Aditama.

Sinambela, Lijan Poltak 2016. Manajemen Sumber Daya Manusia. Jakarta: PT. Bumi Aksara.

Soedarso. Sri Widodo. 2015. Sistem Informasi Manajemen. Badan Penerbit Manggu Media: Bandung.

Sugiyono.2017. Metode Penelitian Manajemen. Cetakan ke-4. Bandung: Penerbit Alfabeta, cv.

Sutrisno. Edy. 2015. Manajemen Sumber Daya Manusia. Jakarta: Penerbit Kencana Predamedia Grop. 